\title{
ACCOUNTABILITY E CONTROLE SOCIAL: UMA REFLEXÃO SOBRE SUA IMPORTÂNCIA E RELAÇÃO PARA A DEMOCRACIA
}

\author{
Renato Pereira Monteiro', Cléber Augusto Pereira², João Luis Peruchena Thomaz ${ }^{3}$
}

\section{RESUMO}

No contexto atual do setor público surgem novos conceitos que redefinem a forma de atuação do setor e de interação entre este e a sociedade. Accountability e controle social são expressões que despontam neste sentido. $\mathrm{O}$ objetivo deste estudo é explorar a existência ou não de relação entre a accountability e o controle social e sua importância para a democracia. Este é um estudo exploratório, quanto aos procedimentos de pesquisa, trata-se de pesquisa bibliográfica por meio de revisão sistemática de literatura. Apurou-se que as reformas no setor público buscam ampliar conceitos de accountability e controle social e reforçar o sistema democrático. Constatou-se que diversos autores confirmam a existência de forte relação entre o controle social e a accountability. Pode-se compreender que existem severas dificuldades de efetivação da accountability e do controle social em países menos desenvolvidos e que existem melhores níveis de accountability e controle social, em países em que a democracia está consolidada há mais tempo.

Palavras-Chave: Accountability. Controle Social. Democracia. Setor Público.

\begin{abstract}
In the contemporary context of the public sector there are new concepts that redefine the way this sector works and its interaction with the society. Accountability and social control are expressions that play a major role in those new concepts. The aim of this study is to explore whether there is a relationship between accountability and social control. This is an exploratory study and was made a sistematic review of literature. The analyse of the relationship was evaluated through the construction of a teoretichal conceptual model. It was found that the reforms in the public sector seek to broaden accountability and social control concepts and reinforce the democratic system. Besides, several authors confirm the existence of a strong relationship between social control and accountability. It is reasonable to understand that there are severe difficulties in implantation of accountability and social control in less developed countries and that there are higher levels of those concepts in countries where democracy is already consolidated.
\end{abstract}

Keywords: Accountability. Social Control. Democracy. Public Sector. Reforms.

\section{1- INTRODUÇÃO}

As reformas na administração pública em diversos países nas últimas décadas introduziram novos conceitos, expressões como accountabilitty e controle social começaram a fazer parte do cotidiano dos gestores públicos, e fomentaram uma série de reformas e medidas que podem conduzir à sua efetivação. Conforme Pinho e Sacramento (2009) pode-se associar

\footnotetext{
${ }^{1}$ Universidade de Aveiro - Portugal

${ }^{2}$ Universidade Federal do Maranhão

${ }^{3}$ Mestre em Contabilidade pela UNISINOS

Volume 5, Número 9

Revista UNEMAT de Contabilidade

Jan./Jul. 2016

ISSN: $2316-8072$
} 
o surgimento da accountability com a emergência do capitalismo nas empresas privadas, devido a necessidade de ser controlada e agir dentro de parâmetros para, posteriormente, ser aplicada também na esfera pública como uma resposta ou rompimento ao patrimonialismo.

Para Keating (2001) a reforma da gestão pública é fundamentalmente uma resposta à crescente insatisfação com o desempenho do governo, na manutenção econômica e desenvolvimento social. Países membros da Organisation for Economic Co-operation and Development (OECD) reformaram seus serviços públicos por causa de preocupações sobre o desempenho econômico, da necessidade de inovação ou de uma série de demandas dos cidadãos e instituições incentivadas por um declínio na confiança dos governos.

Em relação as reformas dos anos 90, Matias-Pereira (2008, p. 75) afirma que na realidade brasileira houve um processo de avanço em relação ao conceito de governança e dos princípios políticos que por fim orientam e incentivam propostas de "participação, accountability, controle social".

A accountability no Brasil surge com a nova constituição e com a consolidação da democracia. Estas alterações prometiam aparelhar o estado de forma a uma atuação mais eficiente e controlável (Pinho \& Sacramento, 2009). Para o Centro Latino-Americano de Administração para o Desenvolvimento (CLAD) o sucesso de ações de accountability depende do desenvolvimento da capacidade dos cidadãos de agir na definição das metas coletivas de sua sociedade e da construção de mecanismos institucionais que garantam o controle público das ações dos governantes ao longo de todo o seu mandato. O termo accountability não possui tradução direta para o português ou sua aplicação não teria ainda sentido completo de aplicação no Brasil (Campos, 1990; Castro, 2011).

Ainda sob esta ótica das reformas Pinho e Sacramento (2009) e Castro (2011) destacam que no Brasil a legislação tem se dedicado a criação de mecanismos que permitam o controle político do estado pela sociedade, mas depende da participação social e do esforço desta para mobilizar-se e assumir seu papel, isto é entendido como controle social. O controle social consite nos mecanismos e espaço que a sociedade em termos de participação e interferência no poder público. Este processo de maior participação popular tem sido reforçado no Brasil. O país tem procurado aplicar técnicas de outros nações em sua gestão pública, a expectativa é que isso seja incorporado na realidade brasileira como reforço ao processo democrático.

A relação direta entre a accountability e o controle social é afirmada quando Silva e Macedo (1998) asseveram "O conceito de accountability é de fundamental importância para 
que possamos falar em participação social nas políticas públicas e responsabilização dos gestores públicos, ou seja, a ideia de controle social da administração pública”. Finalizam destacando que sem controle social (Silva \& Macedo,1998, p.15) “a responsabilização dos gestores (accountability) fica longe de ser atingida".

A relação entre o controle social e a accountability também foi destacada por Miguel (2005, p. 28) afirmando que "Nos estudos sobre democracia, a accountability ganha destaque por prometer um grau razoavelmente alto de controle do povo sobre os detentores do poder político [...]". Ressalta que este controle social é a forma exequível no contexto atual de sociedades populosas, extensas, complexas e especializadas como as contemporâneas. Opina que estes conceitos estão estreitamente vinculados entres si, e, que somente com informações públicas e prestações de contas confiáveis por parte dos gestores da administração pública será possível atingir a accountability pleno, com a participação dos cidadãos efetivamente nas decisões políticas desde que acompanhada de um processo de controle interno e externo fortes. Como contraponto Ceneviva (2006, p. 11) limita a dependência desta relação ao afirmar "Seguramente, a responsabilização por meio do controle social está longe de garantir a existência de uma accountability próxima da ideal".

Diante destes argumentos emergem duas questões de investigação: qual a relação entre a accountability e o controle social? quais práticas adotadas em diferentes países podem comprovar ou refutar esta relação de proximidade afirmada por (Castro, 2011; Matias-Pereira, 2008; Miguel, 2005; Silva e Macedo, 1998), mas que foi indiretamente contraposta por Ceneviva (2006)?

O objetivo geral do estudo é explorar a existência ou não de relação entre a accountability e o controle social através de análise da literatura nacional e internacional relativa às práticas existentes. O estudo está organizado inicialmente apresentado a revisão da literatura que aborda os conceitos de accountability e controle social. Em seguida apresentasse a metodologia do estudo e são analisados e discutidos os estudos encontrados na literatura internacional sobre o tema. O trabalho é encerrado pela apresentação das principais conclusões encontradas.

\section{2- REVISÃO DA LITERATURA}

Nesta seção serão discutidos o conceito de accountability, controle social, a relação deles no contexto Brasil e apresentado o modelo teórico da revisão de literatura. 


\subsection{Accountability no Brasil}

Um dos primeiros debates que será explorado neste estudo é a definição da accountability, para tal recorresse a um dos seus percusores. Segundo Mosher (1968) a accountability é sinônimo da responsabilidade objetiva ou da obrigação de responder a algo ou alguém. Está associada implicitamente a responsabilização pessoal por atos praticados e a necessidade e exigência de prestação de contas, neste sentido a expressão tem sido comumente traduzida como o processo de responsabilização corroboram Miguel (2005), Pinho e Sacramento (2009) e Castro (2011).

Mosher (1968) ainda argumenta que quem falha no cumprimento de diretrizes legítimas é considerado irresponsável e está sujeito a penalidades, destaca que se o dirigente público não é responsável pela função que exerce, é necessário que se estabeleça prêmios e responsabilização para valorizar o exercício da gestão. Posteriormente, Castro (2011, p. 512) reafirma o posicionamento apresentado por Mosher (1968), (1990) a accountability é sinônimo de responsabilidade objetiva ou obrigação de responder por algo: como um conceito oposto a - mas não necessariamente incompatível com - responsabilidade subjetiva. Enquanto a responsabilidade subjetiva vem de dentro da pessoa, a accountability, sendo uma responsabilidade objetiva, "acarreta a responsabilidade de uma pessoa ou organização perante uma outra pessoa, fora de si mesma, por alguma coisa ou por algum tipo de desempenho".

A obra referência do accountability no Brasil é o estudo de Campos (1990). A autora apresentou o posicionamento da maioria dos pesquisadores norte-americanos. Estes acreditavam que o fortalecimento da accountability e o aperfeiçoamento das práticas administrativas são conceitos que se complementam, mas Campos (1990) entende que a accountability é mais amplo não sendo apenas uma questão de desenvolvimento organizacional. Pinho e Sacramento (2009) ao comentar a obra de Campos (1990) ressaltam:

\footnotetext{
"Quando a autora finalmente conclui seu trabalho, em 1988, o qual geraria a publicação do famoso artigo no Brasil em 1990, o país desfrutava de ventos mais democráticos, uma vez que o regime militar já havia sido encerrado, mas muito longe ainda de qualquer prática efetiva de accountability, conforme demonstrou seu estudo.”.
}

Ao refletir sobre a obra de Campos temos que conhecer o contexto em que ela pesquisava e escrevia. Na conjuntura de final de ditatura e início de democracia Campos (1990) ressaltava que embora essencial, o processo eleitoral, por si só, não era ágil bastante para salvaguardar o interesse público. A legitimidade do poder delegado pelo povo ao Estado 
precisa ser assegurada pelo exercício ativo da cidadania, por partidos políticos sintonizados com seus eleitores e por uma opinião pública bem-informada. Pode-se entender que Campos indiretamente fazia referência ao controle social, neste ponto, como forma de participação de eleitores como uma forma de cidadania ativa por meio do exercício do controle social que ainda não estava consolidado na época.

Conforme Pinho e Sacramento (2009) desde o relato de Campos (1990), com a introdução na nova Constituição Federal no Brasil, o cenário da administração pública brasileira foi modificado, através da consolidação da democracia, com o foco da gestão pública em ser mais eficiente e controlável e com o desenvolvimento de pesquisas acadêmicas sob o tema accountability, principalmente como sinônimo de responsabilização.

Autoes que analisarama temática após a década de 90 começaram a interpretar uma séria de responsabilidades envoltas na accountability e aproximá-la ao conceito de controle social. Arato (2002, p. 103) destaca que "No nível do modelo institucional, accountability deve ser complementada por instituições de deliberação, constitucionalismo e representatividade descritiva". Este autor sugere, que a condição de maior relevância para o desenvolver de um sistema de accountability funcional é a atividade e participação dos cidadãos nos fóruns públicos democráticos e na sociedade civil. Miguel (2005, p. 27) acresentou o papel dos legisladores neste processo em relação à capacidade que estes têm de impor sanções aos governantes, notadamente reconduzindo ao cargo aqueles que se desincumbem bem sua missão e destituindo os que possuem desempenho insatisfatório. Inclui a prestação de contas dos detentores de mandato e o veredicto popular sobre essa prestação de contas. Enfatiza que um controle efetivo "é consequência da cidadania organizada; uma sociedade desmobilizada não será capaz de garantir a accountability”.

Esta maior partipação ou cidadania organizada é interpretada neste estudo como como uma forma de controle social. Miguel (2005) aprofundando este entendimento estabeleceu cmo criitério para o funcionamento da accountability que os representantes devem ter poder efetivo para a implantação das políticas que preferem. Alega que a participação e interferência de entidades externas afeta a autonomia do governante, ficando o controle popular comprometido, na medida que as decisões são tomadas $\mathrm{O}$ sentido do controle popular fica comprometido quando parte significativa das decisões são tomadas por organismos como a Organização das Nações Unidas, União Europeia, agências de financiamento entre outros.

Uma das contribuições relevantes dos estudos de Miguel (2005) e Castro (2009) foi identificar que nos países onde a democracia está consolidada o processo de responsabilização 
dos gestores públicos perante seus atos junto aos cidadãos é comum. Para os autores, nestes países as práticas de gestão crescem na mesma proporção em que o accountability é desenvolvido. Para Castro (2011, p. 512) um dos significados da accountability é "uma proteção dos cidadãos às práticas da má gestão", defende assim como Campos (1990) que existe uma relação direta entre o estágio da democracia do país e do desenvolvimento e interesse pela accountability, tendendo a acompanhar os avanços de valores democráticos como igualdade, dignidade humana, participação e representatividade.

Nota-se que as primeiras discussões acerca deste novo conceito surgiram no Brasil na década de 90, mas nos EUA e em outros países mais desenvolvidos o tema já era objetode grandes estudos. Um destes de O’Donnell (1998) foi o pioneiro na distinção e conceituação de diferentes formas da accountability. Sua classificação estabelece uma diferenciação espacial entre accountability vertical e horizontal. Para o autor a expressão pode ser entendido como a responsabilização democrática dos agentes públicos que reúne dois mecanismos: accountability vertical, na qual a sociedade controla de forma ascendente os governantes, mediante o voto em representantes, os plebiscitos e os conselhos de usuários de serviços públicos, entre outros mecanismos, e accountability horizontal, definida como aquela que se efetiva mediante "a fiscalização mútua entre os poderes ou por meio de outras agências governamentais que monitoram o poder público, tais como os tribunais de contas".

Já a OECD, em suas publicações, adota uma definição mais normativa, conceituando accountability como sendo "a obrigação de demonstrar que determinada ação está sendo conduzida de acordo com as regras e padrões acordados, ou que seus resultados estejam sendo reportados honesta e apuradamente pelos programas ou ao longo dos mandatos" (OECD, 2002, p.22). Na seguência do estudo será discutido o conceito de controle social no Brasil.

\subsection{Controle social no Brasil}

Para compreender o significado do controle social no contexto do setor público recorre-se inicalmente a obra de Campos (1990, p. 33) quando este refere que existe uma proporcionalidade em relação ao crescimento e desenvolvimento do setor público e sua importância na vida das pessoas, cresce também a necessidade de garantir que o poder não fique totalmente concentrado nas mãos de um grupo de servidores públicos, pois estes podem não representar os interesses da comunidade. Destaca ainda que quando não existe controle efetitvo e um conjunto de penalidaes que podem ser aplicadas em caso de ilegitimidades a democracia fica enfraquecida. A importância da participação social é também destacada por 
Pereira (1996) ao afirma a aplicabilidade do controle social depende permanentemente da sociedade validar e atestar os serviços prestados, ao mesmo tempo que se estabelecerá um sistema de parceria ou de co-gestão entre a sociedade civil e o Estado.

Já Correia (2000, p. 66) ao tentar explicar "controle social" recorreu sua origem na sociologia. Empregada para designar os mecanismos que estabelecem a ordem social disciplinando a sociedade e submetendo os indivíduos a determinados padrões sociais e princípios morais, destaca ainda que a expressão tem sido alvo das discussões e práticas recentes de diversos segmentos da sociedade como sinônimo de participação social nas políticas públicas. No contexto da administração pública foi concebida na perspectiva de setores organizados da sociedade participarem desde as suas formulações de planos, programas e projetos, ao acompanhamento de suas execuções até a definição da alocação de recursos para que estas atendam aos interesses da coletividade.

Não longe deste entender para Ceneviva (2006) o controle social é uma forma de accountability vertical, retomando O'Donnell. Argumenta que ele não se esgota com o processo eleitoral. Pelo contrário, dá-se de maneira ininterrupta, sem, no entanto, se contrapor às formas clássicas de controle.

Nota-se que para que exista um efetivo controle social é preciso que a participação social, para além do processo eleitoral. Esta participação deve ter espações e ser fomentada por meio de regimes democráticos de participação. No caso do Brasil, como já destacado, o tema ganha espaço com a nova constituição. Matias-Pereira (2008) já vinculam o desenvolvimento do controle social no Brasil há um períod posterior, consoante às reformas na administração pública da década de 90, argumenta que a implantação da New Public Management (NPM) no Brasil buscou delinear um novo padrão de gestão pública, que apoiase essencialmente nos princípios da flexibilidade, ênfase em resultados, foco no cliente e no controle social. Corroboram com estes argumentos Pereira e Medeiros (2005, p. 42) ao comentarem que a reforma administrativa brasileira iniciada em 1995 com o Plano Diretor da Reforma do Aparelho do Estado no Brasil, foi uma tentativa de tornar a administração mais eficiente e trazia como conceito subjacente a orientação de descentralização para outros entes da federação, a execução de políticas públicas e a previsão do controle social.

As reformas permitiram um controle maior do setor público, abriu espaços para a participação da sociedade em conselhos existentes na atualidade em diversos progrmas como Bolsa Famíia, merenda escolar, verbas do Fundo Nacional da Educação entre outros. A importância do acompanhamento (Akutusu e Pinho, 2002) fortalece os controles formais 
legalmente instituídos, colaborando para que a sociedade participe mais ativamente da vida pública, reduzindo a distância entre o desempenho do governo e as efetivas necessidades dos cidadãos.

Diversos autores entendem que para este exercício é necessário um amadurecimento da sociedade em conhecimento de seus direitos e responsabilidades. Silva e Macedo (1998) reiteram que existem dificuldades de controle social em países menos desenvolvidos, como no caso do Brasil. Argumentam que a democracia é a principal prejudicada pela falta de controle social, pois a participação popular normalmente ganha destaque quando participa nas eleições nestes países. Para Silva e Macedo (1998, p. 12) o controle social pressupõe mecanismos formais de atuação da sociedade. Até as camadas mais privilegiadas da sociedade não tem o conhecimento suficiente de como funciona a máquina pública. Os procedimentos são obscuros e não há a publicidade adequada dos atos que afetam diretamente as comunidades.

Miguel (2005) argumenta que a extensão, qualidade e força dos controles são consequência do fortalecimento da malha institucional da sociedade civil quando diferentes interesses se organizam, aumentando a possibilidade dos cidadãos exercerem o controle $\mathrm{e}$ cobrarem do governo aquilo a que têm direito. Com a definição os dois conceitos fundamentais deste estudo, accountability e controle social é possível estruturar um modelo teórico de análise da relação entre eles.

\subsection{Modelo conceitual teórico para análise da inter-relação entre accountability e controle social}

Tanto a accountability como o controle social são elementos resultantes das reformas da administração pública brasileira na década de 90. O modelo teórico apresentado na Figura 1 representa o entendimento de que, tanto a accountability como o controle social, foram introduzidos na administração pública com maior ênfase em razão dos preceitos da NPM. 
Figura 1: Modelo conceitual teórico de análise da inter-relação entre Accountability e Controle Social

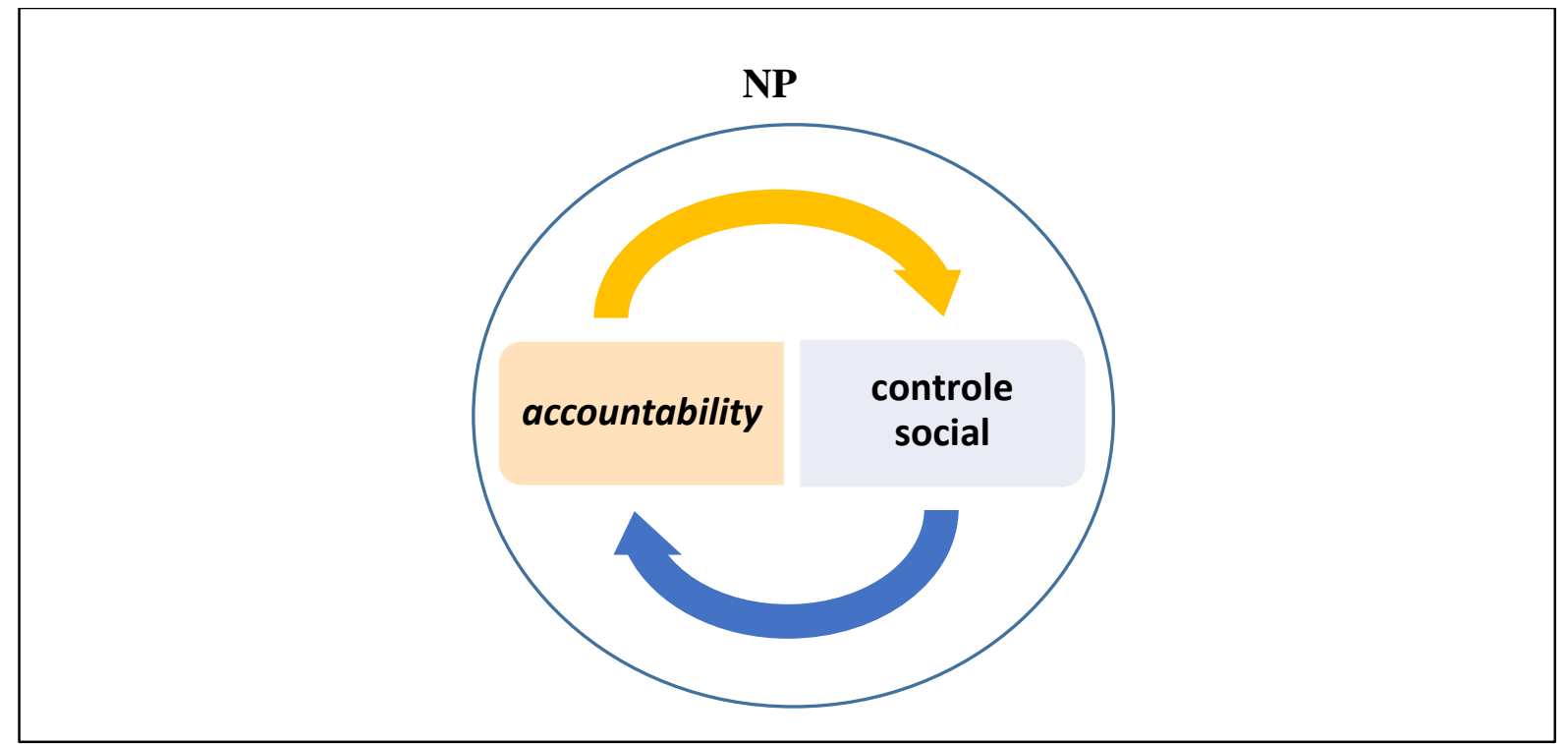

Fonte: Elaborado pelos autores

Por outro lado, não está totalmente evidente a relação direta ou indireta entre os dois elementos sendo que eles, em tese, são originários do mesmo processo de mudança, não sendo claro, nas abordagens destacadas, a forma como cada elemento pode interferir ou contribuir com o outro.

\section{3- METODOLOGIA DO ESTUDO}

O objetivo do estudo que é explorar a existência de relação entre a accountability e o controle social através de análise da literatura nacional e internacional relativa as práticas existentes. Para responder às perguntas de investigação e atender o objetivo deste estudo, utilizou-se a pesquisa bibliográfica. Esta pesquisa foi caracterizada seguindo-se a taxonomia de Raupp e Beuren (2003), referente às tipologias de pesquisa aplicada à contabilidade que as classifica: (1) quanto aos objetivos, (2) quanto aos procedimentos de pesquisa e (3) quanto a abordagem do problema.

A pesquisa, quanto aos seus objetivos, é exploratória. Este posicionamento se justifica em razão da inovação na abordagem aqui realizada, no que se refere a mapear a relação existente entre a accountability e o controle social, utilizando pesquisa exploratória na base de dados da ISI Current Contents disponibilizada pela Thomson Reuters. Em estudos na área da 
ciência contábil, não foram identificadas pesquisas que explorassem a relação em causa neste estudo.

Quanto aos procedimentos trata-se de uma pesquisa bibliográfica (Raupp \& Beuren, 2003, p. 83) "Os procedimentos de pesquisa dizem respeito a como se conduz o estudo e, portanto, se obtém os dados". Este procedimento de pesquisa foi escolhido para evidenciar por meio de resultados obtidos em pesquisas anteriores sobre a accountability e controle social, elementos que permitissem mapear a existência ou não de relação entre os conceitos relevantes para o novo contexto da administração pública moderna.

A pesquisa bibliográfica foi realizada e organizada através de uma revisão sistemática da literatura, baseando-se em uma adaptação de métodos de revisão de literatura para aplicação nas áreas de ciências sociais (Saur-Amaral, 2011a, 2011b; Tranfield Denyer \& Smart, 2003; Tranfield \& Mouchel, 2002) que são: (1) a definição e enquadramento dos objetivos da revisão da literatura; (2) mapeamento da área estudada; (3) síntese e apresentação dos resultados. Estes passos foram adaptados da seguinte maneira:

1) Organização de um protocolo de pesquisa: para o planejamento da busca foi utilizado um protocolo de pesquisa (ver Apêndice A - Protocolo de Pesquisa) para auxílio na definição antes da pesquisa ocorrer, no sentido de permitir o pensar nos critérios de seleção das fontes de informação e garantir que a seleção ocorra de acordo com aquilo que se pretende. $\mathrm{O}$ protocolo de pesquisa baseia-se em uma adaptação de métodos de revisão sistemática de literatura (Saur-Amaral, 2011b; Tranfield et al., 2003; Tranfield \& Mouchel, 2002). O protocolo permitiu criar um roteiro que identifica os passos realizados, bases de dados consultadas, justificativa para a escolha, palavras-chave utilizadas, período de pesquisa, os filtros criados, permitindo que o processo de pesquisa seja repetido por outros pesquisadores para validar o nível de informação encontrada;

2) Pesquisa em base de dados: inserir os critérios e filtros definidos na ficha de pesquisa nas bases de dados;

3) Seleção dos artigos: transportar os resumos, autor e informações de referência para o sistema Mendeley Desktop ${ }^{\circledR}$, realizando a leitura dos resumos, apontando os artigos selecionados e verificando sua disponibilidade integral;

4) Download dos artigos: verificada a disponibilidade da versão integral dos artigos por meio de acesso institucional.

Quanto à abordagem do problema, a pesquisa é classificada como qualitativa. Este enquadramento parte do pressuposto que as entidades a contabilidade é uma ciência social que 
deve apoiar a sociedade e a gestão pública na solução de seus problemas e conflitos, este estudo visa contribuir neste sentido, esclarecendo a relação entre os dois conceitos. A abordagem qualitativa de um problema de pesquisa permite conhecer a natureza de um fenômeno social, permite conhecer a realidade de um problema de forma mais profunda (Raupp \& Beuren, 2003). Tendo em vista os objetivos do estudo a abordagem qualitativa do problema permite tratá-lo com a profundidade necessária.

\section{4- DISCUSSÃO DOS RESULTADOS DA REVISÃO SISTEMÁTICA DE LITERATURA}

Os passos da revisão sistemática, os critérios de inclusão e exclusão utilizados na pesquisa, e os resultados quantitativos sintetizados da pesquisa estão especificados nos Apêndice A, que apresenta os critérios do protocolo de pesquisa realizada na base de dados da ISI Currents Connect. No Apêndice B é apresentada a matriz de artigos selecionada na base de dados da ISI Currents Connect com os artigos previamente selecionados no protocolo de pesquisa do estudo.

Na seção 4.1 são apresentados os resultados dos estudos identificados no levantamento bibliográfico que descrevem as práxis nos demais países do mundo.

\subsection{Resultados das práxis identificadas no mundo discutidas com as do Brasil}

Estudo realizado na Coréia por Im (2011) relatou o trabalho no país para transformar o governo mais eficaz, atuando em frentes como a accountability, controle da corrupção, liberdade e capacidade de resposta. Faz menção ao menor accountability eleitoral da Coréia em relação aos países da OECD. A accountability do governo e responsabilidade interinstitucional vem diminuindo desde 2003. O accountability democrático na Coréia é menor do que em democracias emergentes como Taiwan, República Checa e Hungria, indicando uma fraqueza no accountability vertical tratado por O’Donnell (2003). O relatado neste estudo corrobora a percepção de Campos (1990) e Castro (2011) em relação ao desenvolvimento do accountability e sua relação com o estágio da democracia de cada país, pois conforme crescem os valores democráticos deverá crescer a accountability. Alinhando-se ao indicado por Silva e Macedo (1998) quanto as dificuldades do controle social em países menos desenvolvidos. 
O estudo de $\mathrm{Ma}$ (2012) ilustra as dificuldades da responsabilidade social chinesa, indica que a própria sociedade é uma força poderosa para melhorar a accountability. Ele pode permitir que uma forma de controle social do governo em um regime não-eleitoral. No entanto, a ausência de eleição competitiva tem limitado o desenvolvimento da responsabilidade social na China.

O estudo de Logar (2011) pesquisa nas agências missionárias federais dos EUA as metas de realização de pesquisa que atendem as necessidades de grupos específicos de usuários e como ocorre a distribuição de participantes e responsabilidade social. O apontado neste estudo referenda o exposto por Miguel (2005) quando enfatizou que o controle social e a accountability estão relacionados sendo algo que deve estar na base da construção das instituições dos regimes constitucionais modernos, estabelecer um sistema que permita os controles sociais.

O estudo de Harris (2012) questiona três décadas de reforma educacional centralizada e um concomitante declínio no papel de educação das autoridades locais no Reino Unido, avaliando se o interesse público local na educação está a ser devidamente salvaguardado. Ao reconhecer o "déficit de accountability" que foi criado no sistema de escolas por essas reformas, considera-se que a sua organização por si só não pode continuamente policiar o setor acadêmico e que seria irrealista esperar que o Ministério da Educação pudesse exercer de forma centralizada a melhoria e a intervenção que as autoridades locais podem em relação às suas escolas. Percebe-se que o estudo de Harris (2012) indica uma falta de accountability no sentido expresso por Mosher (1968), quando trata de uma responsabilidade objetiva ou da obrigação de responder alguém.

Ao realizar uma análise interdisciplinar das reformas da gestão responsáveis no setor público do Reino Unido, Humphrey e Miller (2012) identificaram um conjunto de reflexões sobre o desenvolvimento da nova prática de gestão e pesquisa pública, e indicam algumas das obrigações e responsabilidades dos pesquisadores acadêmicos e gestores no contexto da reforma. O estudo destaca a longa data de falhas associadas aos movimentos de reforma da administração pública, bem como o grau limitado de aprendizagem interdisciplinar dentro do campo. Enfatiza-se que é preciso repensar os parâmetros da investigação no setor público, e evitar a compartimentação da investigação em sub-áreas cada vez menores. Reforça a importância de análises históricas, para entender as inter-relações entre as reformas de contabilidade e gestão pública e amplas transformações nas formas de governar a vida econômica e social. O posicionamento adotado por Humphrey e Miller (2012) reforça o 
destacado por Keating (2001) em relação as reformas do setor público e sua importância para o desenvolvimento do controle social e da accountability.

Um exemplo de controle social pode ser percebido durante o processo de deslocamento interno em Pabbo, norte de Uganda, (Mergelsberg, 2012) que apresenta a situação contraditória em que as agências de ajuda, que trabalham na região, informaram a compreensão da crise moral das pessoas, mas descobriu que era impossível conciliar a sua abordagem baseada nos direitos humanos com as medidas locais de controle social destinada a restabelecer os valores morais. Retoma-se neste, contexto a abordagem de Silva e Macedo (1998) sobre as dificuldades de controle social em países menos desenvolvidos.

A preocupação com o controle social foi avaliada na prática administrativa dos Estados Unidos por Short (2012). Motivada por um movimento para reconceituar a legitimidade das agências administrativas em termos de sua política e sua responsabilização. Desenvolve um quadro teórico fundamentado como uma restrição que não está incorporada na doutrina ou política, e sim na forma que a lei e a estrutura de controle político e nas características organizacionais e interações sociais de agências. $\mathrm{O}$ artigo critica modelos de razão política que minam as estruturas sociais e organizacionais, acabando por moldar e restringir o que as agências fazem. O estudo reforça o defendido por O'Donnell $(2003,1998)$ quanto à existência de dois tipos de accountability um vertical e um horizontal, neste caso a falha estaria concentrada na relação do accountability horizontal.

O artigo de Tuohy (2012) examina os casos de reforma política nos sistemas de saúde na Grã-Bretanha, Países Baixos e Canadá. As reformas britânicas e holandesas reagiram de forma diversificada, alterando o equilíbrio de poder, a combinação de instrumentos de controle, e os princípios de organização. Como resultado, os sistemas da Grã-Bretanha e Holanda, foram transformados em sistemas nacionais híbridos distintos. Os processos envolveram uma política de redesenho, marcada pela atividade dos empreendedores institucionais que exploram oportunidades específicas oferecidas pelos programas públicos de combinar recursos públicos e privados em arranjos organizacionais inovadores. $\mathrm{O}$ aumento da importância dos empreendedores institucionais dá maior urgência ao desenho de estruturas de accountability para permitir a avaliação do desempenho. O relatado por Tuohy (2012) confirma a relação exposta por Campos (1990), Miguel (2005) e Castro (2011), quanto a relação entre o desenvolvimento do país e nível de accountability, e reforça a afirmativa de Akutusu e Pinho (2002), em relação à importância da participação social de forma mais ativa, 
para reduzir a distância entre o desempenho do governo e as efetivas necessidades da sociedade, como produto de um controle social efetivo.

Reed \& Reed (2009, p. 3-4) destacam que nas últimas três décadas tem ocorrido grandes mudanças para a economia internacional em decorrência dos avanços tecnológicos e das mudanças organizacionais nas empresas. Dentre as mudanças do processo de globalização econômica está o discurso sobre o desenvolvimento, especialmente em relação ao papel que as empresas devem desenvolver neste contexto. Assim discute-se o cruzamento da ética nos negócios, como o desenvolvimento econômico e social. Reed \& Reed (2009) destacam que as empresas começaram a ser convocadas para serem protagonistas por meio de cooperação com o setor governamental para o desenvolvimento, em áreas como saúde e educação. Este estudo pode ser associado a afirmação de Pinho e Sacramento (2009) de que o surgimento da accountability está relacionada como o desenvolvimento do capitalismo nas empresas privadas como uma necessidade de atuar dentro de parâmetros de responsabilidade, inclusive social.

Noonan, Sabel e Simon (2009) estudaram o caso dos estados de Alabama e Utah nos Estados Unidos, com um enfoque na accountability em relação a tendência do estado de direito buscar institucionalizar o estado do bem-estar. Descrevem que programas de bem-estar estão sendo redesenhados para aumentar a sua capacidade as novas e mutantes necessidades da sociedade. $\mathrm{O}$ artigo relata um modelo emergente de administração responsável, que se esforça para conciliar flexibilidade programática com valores e regras legais. Assim referendam o destacado por Keating (2001), Matias-Pereira (2008), Pinho e Sacramento (2009) que indicam que as reformas no setor público buscam ampliar conceitos de accountability e controle social e reforçam o sistema democrático.

O estudo de Fimreite e Lægreid (2009) aborda a grande reforma da administração da previdência realizada na Noruega. Trata-se de uma fusão dos serviços de administração da seguridade nacional e do emprego combinados com uma colaboração mais formal com a administração dos serviços sociais dos governos locais. A reforma introduziu um modelo de parceria obrigatória entre o governo central e local. Este modelo é um híbrido de hierarquia e rede. $\mathrm{O}$ modelo de parceria foi criado para resolver o dilema representativo da falta de equilíbrio entre o accountability ao governo central e ao conselho local que é um exemplo da relação entre a accountability e o controle social. Este estudo além de corroborar o destacado por autores como Keating (2001); Matias-Pereira (2008); Pinho e Sacramento (2009) que indicam que as reformas no setor público buscam ampliar conceitos de accountability e 
controle social e reforçar o sistema democrático, aprofunda no sentido afirmado por Arauto (2002) e Campos (1990) de que uma grande condição para desenvolver um sistema adequado de accountability é através da participação da sociedade em diferentes em fóruns públicos democráticos na sociedade civil.

O caso do processo de accountability no setor de saúde indiano é relatado por George (2009). Analisando a visão dos administradores governamentais de cuidados de saúde primários e os trabalhadores do distrito Koppal, na Índia. O estudo detalha como esses atores visualizam duas funções de gestão em causa com a accountability interna: fiscalização e ação disciplinar. O contexto descrito por George (2009) contrapõe-se ao especificado por Campos (1990) na relação em que estudiosos norte-americanos indicavam que o fortalecimento da accountability e o fortalecimento das práticas sociais andam juntas.

A baixa participação dos pobres urbanos nas formas de representação democrática é relatada por Davenport (2010). Destaca que o comparecimento às urnas entre os economicamente desfavorecidos é especialmente baixo em eleições municipais. Significa que os cidadãos que mais necessitam dos serviços prestados a nível local não podem ser representados nas decisões políticas que afetam suas vidas diárias, o que acarreta uma falta do controle social no exercício do poder público por aqueles que mais necessitam de serviços públicos. Davenport (2010) dá forte importância ao processo eleitoral, contrapondo o indicado por Ceneviva (2006), ao afirmar que o controle social não se esgota no processo eleitoral.

Adams e Balfour (2010) abordam os desafios éticos da gestão focadas no mercado, e do grau em que aumenta ou diminui a capacidade de contratação do governo de assegurar que as organizações que oferecem serviços públicos irão aderir a práticas éticas e valores públicos, tais como legalidade, transparência e accountability. Relatam que uma das dificuldades na realização da ética nas organizações está centrada no problema das terceirizações, com poucos ou ineficazes controles regulatórios, nas organizações privadas. Consideram que os desafios éticos podem ser melhor tratados ao nível organizacional, propondo uma tipologia da ética organizacional em forma de matriz, de acordo com a posição relativa da organização sobre as dimensões de conformidade e responsabilidade social. Adams e Balfour (2010) destacam a importância do controle no segmento público. Neste sentido cabe retomar a origem sociológica do controle social (Correia, 2000), que é empregada para disciplinar a sociedade e os indivíduos ao agir dentro de determinados padrões sociais e princípios morais.

As tendências de novos programas de assistência social são relatadas por Bach (2010) quando especificam que antes havia um conjunto de programas ostensivamente controlados 
através de leis e regulamentos, atualmente havendo o abandono de estruturas legais e regras tradicionais. Estas novas estruturas de governo estão estreitamente alinhadas com a nova teoria de governança, que mantém a promessa de que é possível redesenhar a organização. Fato que irá produzir um conjunto de políticas que são mais sensíveis às necessidades reais daqueles em situação de pobreza. O estudo argumenta, que os mecanismos de governança prevalecentes da nova agenda da pobreza diminuem em vez de aumentar a responsabilidade e capacidade de resposta, o que reforça que a accountability aprimora a organização institucional. Reporta ao entendimento do foco nas reformas descritas por Keating (2001) e Pinho e Sacramento (2009), indo de encontro ao destacado pela CLAD (2006), quanto ao sucesso da accountability depender do desenvolvimento da capacidade dos cidadãos de agir na definição de metas coletivas e na construção de mecanismos institucionais que garantam o controle público das ações do governo.

Para Arvidson e Lyon (2014) as organizações sem fins lucrativos estão sob crescente pressão para demonstrar o seu impacto social, fazendo alusão às organizações do Reino Unido, analisam a experiência e o comportamento destas em relação a uma demanda por avaliações de impacto social. Destacam que os financiadores de recursos exigem que apresentem provas de como os recursos são utilizados e quais resultados elas têm conquistado. $\mathrm{O}$ estudo demonstra a maior preocupação da sociedade em exercer o controle, mas o caso em questão retrata a realidade em que o sistema democrático já está consolidado, reafirmando o posicionamento de autores como Campos (1990), Silva e Macedo (1998) e Castro (2011).

\section{5- CONCLUSÃO}

O objetivo geral do estudo foi explorar a existência ou não de relação entre a accountability e o controle social através de análise da literatura nacional e internacional relativa as práticas existentes. Para atender ao objetivo da pesquisa realizou-se ampla revisão sistemática na tentativa de coletar estudos para analisar a relação existente e descrita por vários autores e analisada por meio do modelo conceitual teórico de análise ilustrado na Figura 1.

A forte relação entre o controle social e a accountability foi defendida por autores como Campos (1990), Miguel (2005) e Castro (2011) sendo que para este, os conceitos estão estreitamente vinculados entres si, e, que somente com informações públicas e 
accountabilities confiáveis por parte dos gestores da administração pública será possível atingir a accountability pleno, com a participação efetiva dos cidadãos nas decisões políticas (controle social), desde que acompanhada de um processo de controle interno e externo fortes. Ceneviva (2006, p. 11) contrapôs esta dependência limitando-a, quando deixa claro que, em sua opinião, a responsabilização por meio do controle social está longe de garantir a existência de uma accountability próximo da ideal.

Keating (2001), Matias-Pereira (2008) e Pinho e Sacramento (2009) indicam que as reformas no setor público buscam ampliar conceitos de accountability e controle social e reforçar o sistema democrático, fato que foi corroborado pelos estudos de Noonan, Sabel e Simon (2009), Logar (2011) e Tuohy (2012), consolidando o entendimento que existe forte relação entre a accountability, o controle social e o reforço da democrácia.

$\mathrm{O}$ impacto das reformas públicas no desenvolvimento dos conceitos accountability e controle social indicados por Keating (2001), Pinho e Sacramento (2009) e Castro (2011) foi corroborada pelo exposto por Humphrey e Miller (2012).

A dificuldades de efetivação da accountability e do controle social em países menos desenvolvidos referida por Campos (1990), Silva e Macedo (1998) e Castro (2011) foi comprovada por meio da análise dos estudos de Im (2011), principalmente em relação ao accountability e de Ma (2012), com enfoque maior no caso do controle social, e também no de Mergelsberg (2012). Já o melhor nível da accountability e controle social, em países em que a democracia já está consolidada há mais tempo, foi evidenciada pelas abordagens de Harris (2012) e Tuohy (2012).

O sentido de que a accountability não só melhora as organizações internamente conforme questionado por Campos (1990), mas serve também de reforço à democracia, pode também ser constatado pela análise dos estudos de Noonan, Sabel e Simon (2009).

Uma abordagem pertinente ao tema com a possilidade de desenvolver-se novas pesquisas seria buscar evidenciar que práticas legais, conjunto de leis e regulamentos existem nos países que fomentem e incentivam de forma direta a implantação dos objetivos da accountability e do controle social, bem como quais países criam barreiras e limitações para que estes conceitos se desenvolvam em um ambiente de democracia ou não. 


\section{REFERÊNCIAS}

Adams, G. B., \& Balfour, D. L. (2010). Market-Based Government and the Decline of Organizational Ethics. Administration \& Society, 42(6), 615-637.

Aggarwal, R., \& Goodell, J. W. (2013). Political-economy of pension plans: Impact of institutions, gender, and culture. Journal of Banking \& Finance, 37(6), 1860-1879.

Akutusu, L., \& Pinho, J. A. G. D. (2002). Sociedade da informação, accountability e democracia delegativa: investigação em portais de governo no Brasil. Revista de Administração Pública, 36(5), 723-45.

Arato, N. (2002). Representação, soberania popular e accountability. Revista Lua Nova, 55(56), 85-103.

Arvidson, M., \& Lyon, F. (2014). Social Impact Measurement and Non-profit Organisations: Compliance, Resistance, and Promotion. Voluntas, 25(4), 869-886.

Bach, W. A. (2010). Governance, Accountability, and the New Poverty Agenda. Wisconsin Law Review, (2), 239-296.

Campos, A. M. (1990). Accountability: quando poderemos traduzí-lo para o português. Revista de Administracao Publica, 24(2), 32-50.

Castro, D. P. D. (2011). Auditoria, contabilidade e Controle interno no setor público: integração das áreas do ciclo de gestão: contabilidade, orçamento e auditoria e organização dos controles internos, como suporte a governança corporativa. (4th ed.), Atlas: São Paulo.

Ceneviva, R. (2006). Accountability: novos fatos e novos argumentos-uma revisão da literatura recente. In Anais do Encontro de Administração Pública e Governança da Associação Nacional de PósGraduação e Pesquisa em Administração. (pp. 1-17). São Paulo.

Correia, M. V. C. (2000). Que controle social. Os conselhos de saúde como instrumento (pp. 66-73). Rio de Janeiro: Fiocruz.

Davenport, T. C. (2010). Public Accountability and Political Participation: Effects of a Faceto-Face Feedback Intervention on Voter Turnout of Public Housing Residents. Political Behavior, 32(3), 337-368. doi:10.1007/s11109-010-9109-х.

Dorbeck-Jung, B. R., Vrielink, M. J. O., Gosselt, J. F., van Hoof, J. J., \& de Jong, M. D. T. (2010). Contested hybridization of regulation: Failure of the Dutch regulatory system to protect minors from harmful media. Regulation \& Governance, 4(2), 154-174.

Ezzell, M. B. (2012). "I'm in Control": Compensatory Manhood in a Therapeutic Community. Gender \& Society, 26(2), 190-215. 
Fimreite, A. L., \& Lægreid, P. (2009). Reorganizing the welfare state administration. Public Management Review, 11(3), 281-297. doi:10.1080/14719030902798198.

George, A. (2009). "By papers and pens, you can only do so much": views about accountability and human resource management from Indian government health administrators and workers. International Journal of Health Planning and Management, 24(3), 205-224.

Harris, N. (2012). Local Authorities and the Accountability Gap in a Fragmenting Schools System. Modern Law Review, 75(4), 511-546.

Higate, P. (2012). Martial Races and Enforcement Masculinities of the Global South: Weaponising Fijian, Chilean, and Salvadoran Postcoloniality in the Mercenary Sector. Globalizations, 9(1), 35-52.

Humphrey, C., \& Miller, P. (2012). Rethinking impact and redefining responsibility: The parameters and coordinates of accounting and public management reforms. Accounting, Auditing \& Accountability Journal, 25(2), 295-327. doi:10.1108/09513571211198773.

Huse, M., Nielsen, S. T., \& Hagen, I. M. (2009). Women and Employee-Elected Board Members, and Their Contributions to Board Control Tasks. Journal of Business Ethics, 89(4), 581-597.

Im, H. B. (2011). Better democracy, better economic growth? South Korea. International Political Science Review, 32(5), 579-597. doi:10.1177/0192512111419825.

Johansson-Stenman, O., \& Konow, J. (2010). Fair Air: Distributive Justice and Environmental Economics. Environmental \& Resource Economics, 46(2), 147-166.

Justesen, L., \& Mouritsen, J. (2011). Effects of actor-network theory in accounting research. Accounting Auditing \& Accountability Journal, 24(2), 161-193. doi:10.1108/09513571111100672.

Keating, M. (2001). Public Management Reform and Economic and Social Development. OECD Journal on Budgeting, 1(2), 141-212.

Logar, N. (2011). Scholarly science policy models and real policy, RSD for SciSIP in US Mission Agencies. Policy Sciences, 44(3), 249-266.

Ma, J. (2012). The Rise of Social Accountability in China. Australian Journal of Public Administration, 71(2), 111-121.

Maggetti, M. (2014). The rewards of cooperation: The effects of membership in European regulatory networks. European Journal of Political Research, 53(3), 480-499.

Martinez, M. G., Verbruggen, P., \& Fearne, A. (2013). Risk-based approaches to food safety regulation: what role for co-regulation? Journal of Risk Research, 16(9), 1101-1121. 
Matias-Pereira, J. (2008). Administração pública comparada: uma avaliação das reformas administrativas do Brasil, EUA e União Européia. Revista de Administração Pública, 42(1), $61-82$.

Mergelsberg, B. (2012). The displaced family: moral imaginations and social control in Pabbo, northern Uganda. Journal of Eastern African Studies, 6(1), 64-80.

Michaels, J. D. (2010). Privatization's Pretensions. University of Chicago Law Review, 77(2), $717-780$.

Miguel, L. F. (2005). Impasses da accountaability: dilemas e alternativas da representatividade política. Revista de Sociologia e Política, 25, 25-38.

Mosher, F. (1968). Democracy and the public service. (vol. 53) Oxford University: New York.

Noonan, K. G., Sabel, C. F., \& Simon, W. H. (2009). Legal Accountability in the ServiceBased Welfare State: Lessons from Child Welfare Reform. Law \& Social Inquiry, 34(3), 523568. doi:10.1111/j.1747-4469.2009.01157.x.

O'Donnell, G. (2003). Horizontal accountability: the legal institutionalization of mistrust. Democratic Accountability in Latin America, 22, 34-55.

O'Donnell, G. A. (1998). Horizontal accountability in new democracies. Journal of democracy, 9(3), 112-126.

Pereira, L. C. B. (1996). Da administração pública burocrática à gerencial. Revista do Serviço Público, 47(1), 1-28.

Pereira, C. V., \& Medeiros, P. H. R. (2005). O controle social eo Tribunal de Contas da União: o caso dos conselhos de alimentação escolar. Retrieved January 6, 2015, from http://www.tcu.gov.br, 42.

Pinho, J. A. G. de, \& Sacramento, A. R. S. (2009). Accountability: já podemos traduzi-la para o português? Revista de Administração Pública, 43(6), 1343-1368.

Raupp, F. M., \& Beuren, I. M. (2003). Metodologia da pesquisa aplicável às ciências sociais. Como elaborar trabalhos monográficos em contabilidade: teoria e prática. (3th ed.) Atlas: São Paulo.

Reed, A. M., \& Reed, D. (2009). Partnerships for Development: Four Models of Business Involvement. Journal of Business Ethics, 90, 3-37. doi:10.1007/s10551-008-9913-y.

Saur-Amaral, I. (2011a). Revisão sistemática da literatura com apoio de Endnote X5 e NVivo 9. (1st ed.) Bubok: Aveiro.

Saur-Amaral, I. (2011b). Towards a Methodology for Literature Reviews in Social Sciences. Investigação e Intervenção em Recursos Humanos. 
Schwartz, J., Steffensmeier, D. J., \& Feldmeyer, B. (2009). Assessing Trends in Women's Violence via Data Triangulation: Arrests, Convictions, Incarcerations, and Victim Reports. Social Problems, 56(3), 494-525.

Short, J. L. (2012). The political turn in American administrative law: Power, rationality, and reasons. Duke Law Journal, 61(8), 1811-1881.

Silva, F. C. D. C., \& Macedo, F. (1998). Controle e reforma da administração no Brasil. In Encontro Nacional da ANPAD (p. 22). Foz do Iguaçu.

Somerville, P. (2009). Understanding community policing. Policing-an International Journal of Police Strategies \& Management, 32(2), 261-277.

Swamynathan, G., Almeroth, K. C., \& Zhao, B. Y. (2010). The design of a reliable reputation system. Electronic Commerce Research, 10(3-4), 239-270. doi:10.1007/s10660010-9064-y.

Tranfield, D., Denyer, D., \& Smart, P. (2003). Towards a methodology for developing evidence- informed management knowledge by means of systematic review. British journal of management, 14(3), 207-222.

Tranfield, D., \& Mouchel, D. D. (2002). Developing an evidence-based approach to management knowledge using systematic review. Advanced Management Research Centre: Cranfield School of Management.

Tuohy, C. H. (2012). Reform and the Politics of Hybridization in Mature Health Care States. Journal of Health Politics Policy and Law, 37(4), 611-632. 


\section{APÊNDICE A: PROTOCOLO DE PESQUISA}

\begin{tabular}{|c|c|}
\hline Cont & Explicação \\
\hline $\begin{array}{c}\text { Objetivo da } \\
\text { pesquisa }\end{array}$ & $\begin{array}{l}\text { Realizar uma pesquisa de revisão de literatura com as palavras-chave } \\
\text { previamente definidas. O objetivo é identificar e selecionar na literatura os } \\
\text { trabalhos recentes que versam sobre Accountability e Controle Social } \\
\text { baseando-se em artigos de qualidade acadêmica, de fontes de publicação } \\
\text { relevantes e publicados em journals de qualidade internacional e citados, no } \\
\text { mínimo } 1 \text { vez. }\end{array}$ \\
\hline $\begin{array}{l}\text { Equações de } \\
\text { pesquisa a } \\
\text { experimenta } \\
\text { r }\end{array}$ & $\begin{array}{l}\text { As palavras-chave que formam a equação de pesquisa são: "social control" e } \\
\text { "accountability". }\end{array}$ \\
\hline $\begin{array}{l}\text { Âmbito da } \\
\text { pesquisa }\end{array}$ & $\begin{array}{l}\text { Delimitação do espaço de pesquisa: } \\
\text { A base de dados escolhida para a busca foi a ISI Current Contents } \text { Connect } \\
\text { da Thomson Reuters. } \\
\text { - Serão avaliadas as publicações e utilizadas apenas as fontes de } \\
\text { publicação que possuam publicações nas áreas de Social Sciences, } \\
\text { Government Law e Business Economics. } \\
\text { - Período de pesquisa: resultados procurados no período entre } 2009 \text { e } \\
\text { 2014. } \\
\text { - Será realizada a leitura de todos os títulos e resumos/abstracts } \\
\text { previamente selecionados para verificar quais publicações se enquadram na } \\
\text { área desejada. } \\
\text { - Somente serão incluídos os artigos de journals com reputação } \\
\text { relevante. }\end{array}$ \\
\hline $\begin{array}{r}\text { Crite } \\
\text { inc }\end{array}$ & $\begin{array}{l}\text { - Fontes de Publicação que possuam no título: "social control" e } \\
\text { "accountability". } \\
\text { - Publicações da área de Business Economics; } \\
\text { - Publicações da área de Social Sciences; } \\
\text { - Publicações da área de Government Law; } \\
\text { - Publicações encontradas entre } 2009 \text { a 2014, citadas no mínimo } 1 \text { vez. }\end{array}$ \\
\hline $\begin{array}{l}\text { Critérios de } \\
\text { exclusão }\end{array}$ & $\begin{array}{l}\text { - Publicações fora da área Social Sciences, Government Law e Business } \\
\text { Economics; } \\
\text { - Publicações fora do período de } 2009 \text { a } 2014 ; \\
\text { - Publicações diferentes de "artigos completos". }\end{array}$ \\
\hline $\begin{array}{l}\text { Critérios de } \\
\text { qualidade e } \\
\text { validade } \\
\text { metodológic } \\
\quad \text { a }\end{array}$ & $\begin{array}{l}\text { Registrar todos os passos realizados durante a pesquisa e justificação } \\
\text { das decisões tomadas (transparência); } \\
\text { - Será feita a leitura de todos os títulos e seus abstracts para } \\
\text { confirmação se realmente a publicação analisada está dentro da vertente } \\
\text { desejada. }\end{array}$ \\
\hline
\end{tabular}




\section{1) Procedimento de pesquisa inicial:}

a) acesso a base de dados, via acesso institucional, no endereço web em: http://apps.webofknowledge.com

b) acesso a: Procura Básica (basic search)

c) Foram preenchidos os campos com a seguinte equação de pesquisa:

Keyword: ("social control”) - Procurar em (tópico)

AND

Keyword: (accountability) - Procurar em (tópico)

2) Resultados encontrados:

a) Foram encontradas previamente $\mathbf{9 0 6}$ fontes de publicação.

Tabela continua... 
APÊNDICE A: PROTOCOLO DE PESQUISA (continuação)

\begin{tabular}{|l|ll|}
\hline & \multicolumn{3}{|l|}{ 3) Critérios de inclusão realizados: } \\
\hline a) & Selecionados artigos do domínio de pesquisa de Social Sciences; \\
b) & Selecionados artigos da área de pesquisa: Business Economics; Social Sciences; \\
Public Administration, e; Government Law; \\
c) & Selecionados somente os documentos do tipo "article"; \\
d) & Limitada pesquisa a artigos do período entre 2009 e 2014; \\
e) & Limitada a artigos publicados em veículos do tipo "journals"; \\
f) & Ordenados os resultados por ordem decrescente de quantidade de citações e \\
selecionados os artigos com número de citações maior ou igual a 1.
\end{tabular}




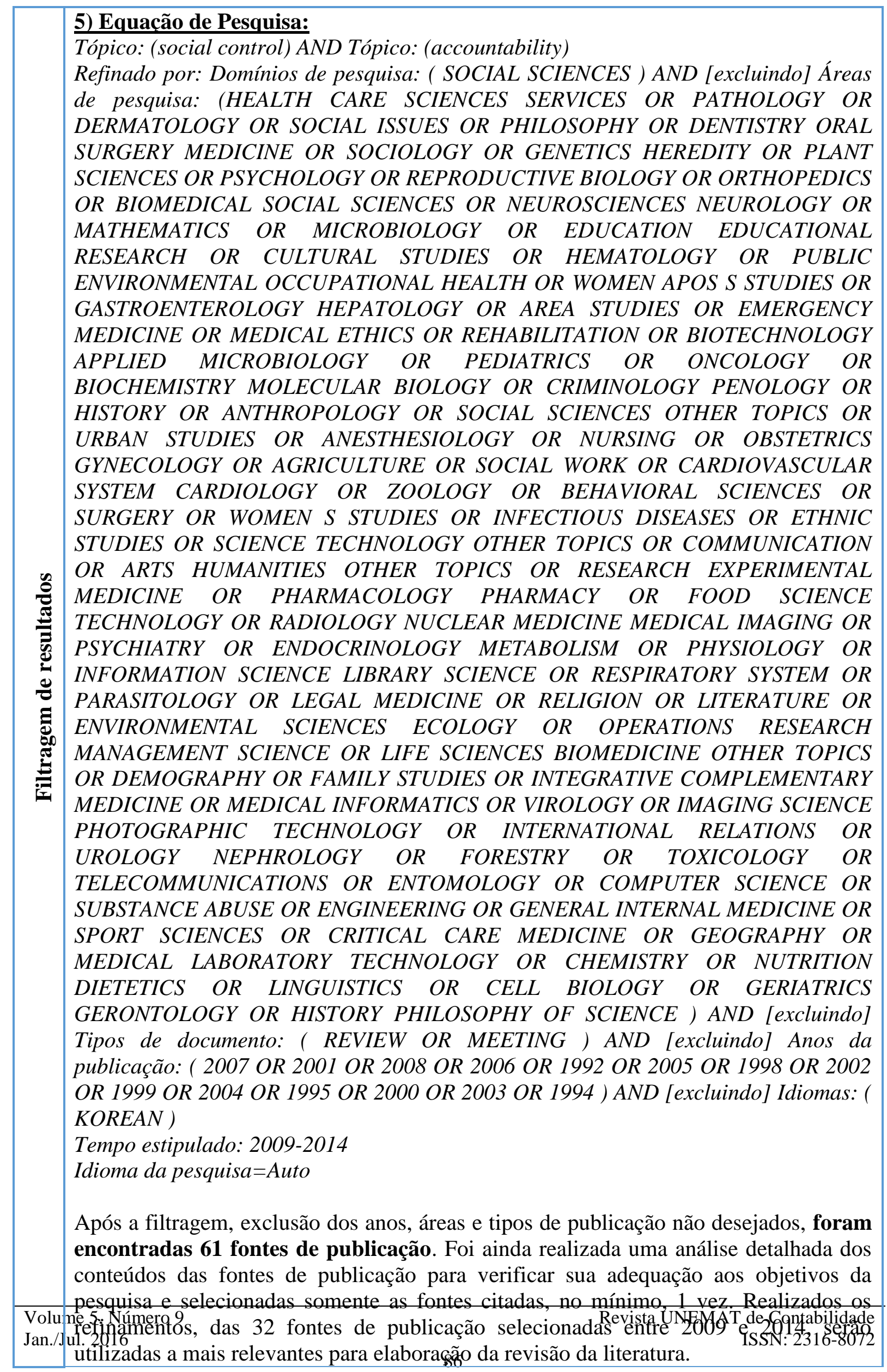




\section{6) Fontes de Publicacão selecionadas}

Ao término do procedimento remanesceram 32 fontes de publicação (2009-2014) que irão subsidiar a revisão de literatura deste trabalho. Os artigos foram exportados ao gerenciador de referências e seus arquivos completos, em formato pdf, individualmente anexados para permitir a leitura.

Fim da tabela. 